\section{Response to: 'Off-label use of tofacitinib: a potential treatment option for SAPHO syndrome' by Xie et al}

We would like to thank Xie et $a l^{1}$ for their interest in our paper ${ }^{2}$ and for their insights into the possible mechanism of action of tofacitinib in synovitis, acne, pustulosis, hyperostosis, and osteitis (SAPHO) syndrome and the trend of stratified medicine.

As Xie et al highlighted, tofacitinib presented clinical and radiological efficacy in patients with SAPHO syndrome who had an inadequate response to tumour necrosis factor (TNF) inhibitors or bisphophonates. Similarly, a clinical trial proved that tofacitinib was effective in patients with TNF inhibitor-resistant psoriatic arthritis (PsA). ${ }^{3}$ By inhibiting the Janus kinase-signal transducer and activator of transcription (JAK-STAT) pathway, tofacitinib modulates the network of a wide range of inflammatory cytokines, including interleukin-6 (IL-6), IL-17 and TNF- $\alpha$, which were potentially involved in the pathogenesis of SAPHO syndrome. ${ }^{4-10}$ We speculated that the multipathway inhibitory effect of tofacitinib might contribute to its efficacy in refractory SAPHO syndrome.

The heterogeneity of treatment response also raises the issue of stratified treatment approach in SAPHO syndrome. Clinical and genetic markers have been identified using machine learning to enable prediction of treatment responses to anti-TNF agents in rheumatoid arthritis. ${ }^{11}$ Furthermore, Miyagawa et al proved that strategic treatment based on immunological phenotypes of the individual patient yielded a significant decrease in disease activity compared with routine treatment in PsA. ${ }^{12}$ Given the high heterogeneity of SAPHO syndrome, we believe that further efforts in precision medicine may facilitate the understanding and management of the disease.

As mentioned by Xie et al, our retrospective study had a limited sample size and follow-up time. It was the first step to demonstrate a new potential treatment for SAPHO syndrome. Future controlled perspective study with a larger sample size and longer follow-up duration is required to establish the efficacy and safety of tofacitinib in SAPHO syndrome.

\footnotetext{
Yueting Li $\odot,{ }^{1}$ Yihan Cao, ${ }^{2}$ Chen Li $\odot,{ }^{3}$ Wen Zhang ${ }^{1}$

'Department of Rheumatology, Peking Union Medical College Hospital, Chinese Academy of Medical Science \& Peking Union Medical College, National Clinical Research Center for Dermatologic and Immunologic Diseases (NCRC-DID), Beijing, China

${ }^{2}$ Department of Radiology, Peking Union Medical College Hospital, Peking Union Medical College and Chinese Academy of Medical Sciences, Beijing, China ${ }^{3}$ Department of Traditional Chinese Medicine, Peking Union Medical College Hospital, Peking Union Medical College and Chinese Academy of Medical Sciences, Beijing, China

Correspondence to Dr Chen Li, Department of Traditional Chinese Medicine, Peking Union Medical College Hospital, Beijing, China; casio1981@163.com and Professor Wen Zhang, Department of Rheumatology, Peking Union Medical College Hospital, Beijing, China; zhangwen91@sina.com
}

Handling editor Josef S Smolen
Contributors $Y L$ and $Y C$ prepared the manuscript and contributed equally to this article. All the authors have critically revised and approved the manuscript.

Funding The authors have not declared a specific grant for this research from any funding agency in the public, commercial or not-for-profit sectors.

Competing interests None declared.

Patient and public involvement Patients and/or the public were not involved in the design, conduct, reporting or dissemination plans of this research.

Patient consent for publication Not required.

Provenance and peer review Commissioned; internally peer reviewed.

(c) Author(s) (or their employer(s)) 2020. No commercial re-use. See rights and permissions. Published by BMJ.

\section{Check for updates}

To cite Li Y, Cao Y, Li C, et al. Ann Rheum Dis Epub ahead of print: [please include Day Month Year]. doi:10.1136/annrheumdis-2020-217956

Received 20 May 2020

Accepted 21 May 2020

\section{Linked}

- https://doi.org/10.1136/annrheumdis-2020-217854

Ann Rheum Dis 2020;0:1. doi:10.1136/annrheumdis-2020-217956

\section{ORCID iDs}

Yueting Li http://orcid.org/0000-0002-9018-6237

Chen Li http://orcid.org/0000-0001-5700-3622

\section{REFERENCES}

1 Wenhui Xie HH, Zhang Z. Off-Label use of tofacitinib: a potential treatment option for SAPHO syndrome. Ann Rheum Dis 2020:10.1136/annrheumdis-2020-217854.

2 Li Y, Huo J, Cao Y, et al. Efficacy of tofacitinib in synovitis, acne, pustulosis, hyperostosis and osteitis syndrome: a pilot study with clinical and MRI evaluation. Ann Rheum Dis 2020. doi:10.1136/annrheumdis-2020-217250

3 Gladman D, Rigby W, Azevedo VF, et al. Tofacitinib for psoriatic arthritis in patients with an inadequate response to TNF inhibitors. N Engl J Med 2017;377:1525-36.

4 Gao W, McGarry T, Orr C, et al. Tofacitinib regulates synovial inflammation in psoriatic arthritis, inhibiting STAT activation and induction of negative feedback inhibitors. Ann Rheum Dis 2016;75:311-5.

5 Rosengren S, Corr M, Firestein GS, et al. The JAK inhibitor CP-690,550 (tofacitinib) inhibits TNF-induced chemokine expression in fibroblast-like synoviocytes: autocrine role of type I interferon. Ann Rheum Dis 2012;71:440-7.

6 Maeshima K, Yamaoka K, Kubo S, et al. The JAK inhibitor tofacitinib regulates synovitis through inhibition of interferon- $\gamma$ and interleukin-17 production by human $C D 4+T$ cells. Arthritis Rheum 2012;64:1790-8.

7 Daoussis D, Konstantopoulou G, Kraniotis P, et al. Biologics in SAPHO syndrome: a systematic review. Semin Arthritis Rheum 2019;48:618-25.

8 Firinu D, Barca MP, Lorrai MM, et al. TH17 cells are increased in the peripheral blood of patients with SAPHO syndrome. Autoimmunity 2014;47:389-94.

9 Hurtado-Nedelec M, Chollet-Martin S, Nicaise-Roland P, et al. Characterization of the immune response in the synovitis, acne, pustulosis, hyperostosis, osteitis (SAPHO) syndrome. Rheumatology 2008;47:1160-7.

10 Zhang S, Li C, Zhang S, et al. Serum levels of proinflammatory, anti-inflammatory cytokines, and RANKL/OPG in synovitis, acne, pustulosis, hyperostosis, and osteitis (SAPHO) syndrome. Mod Rheumatol 2019;29:523-30.

11 Guan Y, Zhang H, Quang D, et al. Machine learning to predict anti-tumor necrosis factor drug responses of rheumatoid arthritis patients by integrating clinical and genetic markers. Arthritis Rheumatol 2019;71:1987-96.

12 Miyagawa I, Nakayamada S, Nakano K, et al. Precision medicine using different biological DMARDs based on characteristic phenotypes of peripheral Thelper cells in psoriatic arthritis. Rheumatology 2019;58:336-44. 